\title{
CORRECTION
}

\section{Correction to: Expanding controlled donation after the circulatory determination of death: statement from an international collaborative}

\author{
Beatriz Domínguez-Gil ${ }^{1} \mathbb{0}$, Nancy Ascher ${ }^{2}$, Alexander M. Capron ${ }^{3}$, Dale Gardiner ${ }^{4}$, Alexander R. Manara ${ }^{5}$, \\ James L. Bernat ${ }^{6}$, Eduardo Miñambres ${ }^{7}$, Jeffrey M. Singh ${ }^{8}$, Robert J. Porte ${ }^{9}$, James F. Markmann ${ }^{10}$, \\ Kumud Dhital ${ }^{11}$, Didier Ledoux ${ }^{12}$, Constantino Fondevila ${ }^{13}$, Sarah Hosgood ${ }^{14}$, Dirk Van Raemdonck ${ }^{15}$, \\ Shaf Keshavjee ${ }^{16}$, James Dubois ${ }^{17}$, Andrew McGee ${ }^{18}$, Galen V. Henderson ${ }^{19}$, Alexandra K. Glazier ${ }^{20}$, \\ Stefan G. Tullius ${ }^{21}$, Sam D. Shemie ${ }^{22}$ and Francis L. Delmonico ${ }^{23,24^{*}}$
}

๑) 2021 Springer-Verlag GmbH Germany, part of Springer Nature

\section{Correction to: Intensive Care Med (2021) https://doi.org/10.1007/s00134-020-06341-7}

The article "Expanding controlled donation after the circulatory determination of death: statement from an international collaborative", written by Domínguez-Gil, B., Ascher, N., Capron, A.M. et al. was originally published electronically on the publisher's internet portal on 21 February 2021 without open access. With the author(s)' decision to opt for Open Choice the copyright of the article changed on 25 March 2021 to () The Author(s) 2021 and the article is forthwith distributed under a Creative Commons Attribution this article is licensed under a Creative Commons Attribution-NonCommercial 4.0 International License, which permits any non-commercial use, sharing, adaptation, distribution and reproduction in any medium or format, as long as you give appropriate credit to the original author(s) and the source, provide a link to the Creative Commons licence, and indicate if changes were made. The images or other third party material in

\footnotetext{
*Correspondence: Francis_Delmonico@neds.org

${ }^{23}$ Chief Medical Officer, New England Donor Services, 60 1st Ave, Waltham, MA 02451, USA

Full author information is available at the end of the article
}

The original article can be found online at https://doi.org/10.1007/ s00134-020-06341-7. this article are included in the article's Creative Commons licence, unless indicated otherwise in a credit line to the material. If material is not included in the article's Creative Commons licence and your intended use is not permitted by statutory regulation or exceeds the permitted use, you will need to obtain permission directly from the copyright holder. To view a copy of this licence, visit http://creativecommons.org/licenses/by-nc/4.0/.

The original article has been corrected.

\footnotetext{
Author details

${ }^{1}$ Director General, Organización Nacional de Trasplantes, Madrid, Spain. ${ }^{2}$ Department of Surgery, University of California, San Francisco, CA, USA. ${ }^{3}$ Scott H. Bice Chair in Healthcare Law, Policy and Ethics, Department of Medicine and Law, University of Southern California, Los Angeles, CA, USA. ${ }^{4}$ Intensive Care Medicine, Nottingham University Hospitals NHS Trust, Nottingham, UK. ${ }^{5}$ Consultant in Intensive Care Medicine, The Intensive Care Unit, Southmead Hospital, North Bristol NHS Trust, Bristol, UK. ${ }^{6}$ Department of Neurology and Medicine, Active Emeritus, Dartmouth Geisel School of Medicine, Hanover, NH, USA. ${ }^{7}$ Transplant Coordination Unit and Service of Intensive Care, University Hospital Marqués de Valdecilla-IDIVAL, School of Medicine, University of Cantabria, Santander, Spain. ${ }^{8}$ University of Toronto, and Trillium Gift of Life Network, Toronto, Canada. ${ }^{9}$ Department of Surgery, University Medical Center Groningen, Groningen, The Netherlands. ${ }^{10}$ Department of Surgery, Massachusetts General Hospital, Boston, MA, USA. ${ }^{11}$ Department of Cardiothoracic Surgery, Sant Vincent'S Hospital, Sidney, Australia. ${ }^{12}$ Department of Anesthesia and Intensive Care, University of Liège, Liège, Belgium. ${ }^{13}$ General and Digestive Surgery, Hospital Clínic, IDIBAPS, CIBERehd, University of Barcelona, Barcelona, Spain. ${ }^{14}$ Department of Surgery, University of Cambridge, Cambridge, UK. ${ }^{15}$ University Hospitals Leuven and Catholic University Leuven, Leuven, Belgium. ${ }^{16}$ Toronto General Hospital, University of Toronto, Toronto, Canada. ${ }^{17}$ Bioethics Research Center,
} 
Department of Medicine, Washington University School of Medicine, St. Louis, MO, USA. ${ }^{18}$ Australian Centre for Health Law Research, Faculty of Law, Queensland University of Technology, Brisbane City, Australia. ${ }^{19}$ Director of Neurocritical Care, Brigham and Women's Hospital, Harvard Medical School, Boston, MA, USA. ${ }^{20}$ Chief Executive Officer, New England Donor Services, Walthan, MA, USA. ${ }^{21}$ Division of Transplant Surgery, Brigham and Women's Hospital, Harvard Medical School, Boston, MA, USA. ${ }^{22}$ Pediatric Intensive Care, Montreal Children's Hospital, McGill University, Medical Advisor, Deceased

Donation, Canadian Blood Services, Montreal, Canada. ${ }^{23}$ Chief Medica Officer, New England Donor Services, 60 1st Ave, Waltham, MA 02451, USA
${ }^{24}$ Department of Surgery, Harvard Medical School at Massachusetts General Hospital, 55 Fruit Street, Boston, MA 02114, USA.

Publisher's Note Springer Nature remains neutral with regard to jurisdictional claims in published maps and institutional affiliations.

Published online: 15 June 2021 